\title{
Fishery-independent estimation of benthic species density - a novel approach applied to Norway lobster Nephrops norvegicus
}

\author{
Paulo Fonseca ${ }^{1, *}$, Paulo Lobato Correia ${ }^{2,3}$, Aida Campos $^{1}$, Phooi Yee Lau ${ }^{2}$, \\ Victor Henriques ${ }^{1}$
}

\author{
${ }^{1}$ INRB/L-IPIMAR - Portuguese Institute of Biological Resources/Laboratory of Fisheries and Sea Research, \\ Avenida de Brasília, 1449-006 Lisboa, Portugal \\ ${ }^{2}$ Institute of Telecommunications, Avenida Rovisco Pais, 1049-001 Lisboa, Portugal \\ ${ }^{3}$ Instituto Superior Técnico/Technical University of Lisbon, Avenida Rovisco Pais, 1049-001 Lisboa, Portugal
}

\begin{abstract}
The use of image-based technologies has gained increasing importance in marine research, particularly in benthic habitat classification and the assessment of epibenthic commercial species. A common application that has now entered into the routine of a number of northeastern Atlantic research institutes and in the Mediterranean (on an irregular basis) is fishery-independent estimation of Norway lobster Nephrops norvegicus abundance. Typically, the experimental set-up consists of a video camera mounted on a sledge towed from a research vessel during targeted surveys. Targeted surveys produce superior images; however, fishing operations cannot be carried out simultaneously, which limits the amount of information collected. During a research cruise testing the use of by-catch reduction devices (BRD) to optimise the fishing pattern of Norway lobster, an underwater video camera was hung from the trawl headline, angled down in the tow direction to register ground images. We evaluated the potential usefulness of this set-up as an alternative to traditional methods for the study of benthic habitats and present a case study of the Norway lobster. A preliminary estimate of burrow entrance density $\left(2.1 \mathrm{~m}^{-2}\right)$ in Portuguese waters was obtained by superimposing a measuring grid over individual image frames. The combined approach (video recording while trawling) also allowed a first estimate of the survey trawl efficiency (0.46). The advantages (e.g. simultaneous image and lobster samples) and disadvantages (e.g. low quality image due to the high trawling speed and mud clouds) of the experimental set-up are discussed, concluding by its practicability. However, its application to Norway lobster density estimation as an alternative to current procedures will require further development.
\end{abstract}

KEY WORDS: Video surveys $\cdot$ Benthic habitats $\cdot$ Norway lobster $\cdot$ Abundance estimation $\cdot$ Burrow density $\cdot$ Canadian grid $\cdot$ Portugal

\section{INTRODUCTION}

The use of image-based technologies is increasing in benthic habitat classification and monitoring of marine biodiversity. Fine-scale spatial data can provide accurate information on the distribution and abundance of commercially valuable species, e.g. fishery-independent estimation of Norway lobster Nephrops norvegicus abundance. This aplication is now routine in a number of northeastern Atlantic research institutes (Bailey et al. 1993, Tuck et al. 1997) and, on an irregular basis, in the Mediterranean (Smith et al. 2003, Aguzzi et al. 2004, Morello et al. 2007).

The typical set-up consists of a video camera mounted on a metal sledge towed from the stern of a research vessel during targeted surveys. While it has the advantage of being a targeted methodology, which allows good control of the factors influencing image 
acquisition, such as towing speed or camera inclination, this procedure limits the simultaneous pursuit of complementary or alternative objectives during the same cruise.

In Portuguese continental waters, bottom trawled deep-sea crustaceans (shrimps and Norway lobster) are among the most valuable species caught, attracting extremely high prices at auction. Their economical relevance and the concern about the state of the Norway lobster stock led implementation of a Recovery Plan (EC 2005). During a research cruise in July 2005 aimed at testing by-catch reduction devices (BRD), which promote the escape of undersized Norway lobsters (Fonseca et al. 2006), video footage from the Norway lobster fishing grounds was captured by a camera hung on the trawl headline. The main objective was to evaluate the adequacy of this set-up as an alternative fisheries-independent method for estimation of Norway lobster abundance, and to provide a preliminary estimate of the burrow density of these crustaceans in southern European Atlantic waters.

\section{MATERIALS AND METHODS}

Location of experimental settings. During July 2005, we made a total of 46 tows using a low opening $(1 \mathrm{~m})$ survey bottom trawl from the RV 'Noruega' (IPIMAR: Portuguese Laboratory of Fisheries and Sea Research vessel) off the continental Portuguese south coast. The trawls were in Norway lobster fishing grounds located on the Faro plateau from ca. 400 to $600 \mathrm{~m}$ depth (east of Cape Sta. Maria) (Fig. 1). During some of the tows, the UWVC (underwater video acquisition system) was installed on the main body of the trawl facing aft, so that the mechanical performance of the BRD used could be evaluated along with behavioural observations of target species. Five tows were made with the camera mounted on the trawl headline, angled down

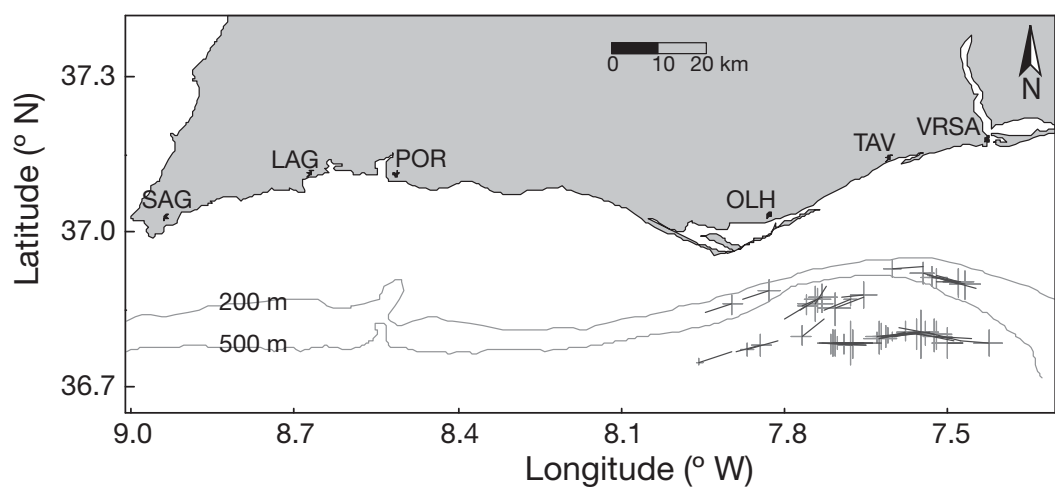

Fig. 1. Map of the Portuguese south coast showing tow tracks and their starting points (straight lines and crosses). Coastal towns: SAG, Sagres; LAG, Lagos; POR, Portimão; OLH, Olhão; TAV, Tavira; VRSA, Vila Real de Santo António at $45^{\circ}$ to record ground images. The results presented herein refer to a single tow (geographical position $36^{\circ} 53.9^{\prime} \mathrm{N}, 7^{\circ} 28.0^{\prime} \mathrm{W}$ and $36^{\circ} 54.5^{\prime} \mathrm{N}, 7^{\circ} 30.5^{\prime} \mathrm{W}$; depth $420 \mathrm{~m}$ ) in which about $18 \mathrm{~min}$ of images with acceptable quality were captured. In other hauls, mud clouds raised by the otterboards produced images of unacceptable quality. All tows were carried out during daylight at a towing speed of about 3.0 knots (GPS data), and the effective haul duration (gear fishing on the bottom) was $1 \mathrm{~h} \mathrm{tow}^{-1}$. Trawl geometry (wingend and door spread, vertical opening) and towing speed were continually monitored using Scanmar sensors.

Video equipment characteristics and set-up. The UWVC used comprises a Kongsberg Maritime OE 1324 monochrome low-light intensity SIT camera fitted in a $3000 \mathrm{~m}$ depth-rated titanium alloy housing. The camera has a light sensitivity (limiting) of $2 \times 10^{-4}$ lux, a Hi8 recording format and power source assembled in a cylindrical aluminium alloy casing (rated to a maximum working depth of $1500 \mathrm{~m}$ ). A single $75 \mathrm{~W}$ light bulb was used as a light source.

The camera and the light were mounted on a metal frame hung on the trawl headline facing down at an angle of $45^{\circ}$. During the tow, the distance from the camera to bottom was around $1 \mathrm{~m}$ (Scanmar headline height sensor readings). Prior to the start of each tow, the system was programmed (start time lag and total recording time) with a dedicated graphical user interface PC software. The position of the camera assembly in the trawl is shown in Fig. 2.

Area estimation and burrow counting procedure. Ground area was estimated from video images using a gridding technique, known as the 'Canadian grid' (Grassle et al. 1975, Wakefield \& Genin 1987), which has long been used in marine research as a quantitative analysis tool for benthic organism density estimation (e.g. Lauth et al. 2004a,b). The video footages were processed for estimation of burrow density. To do this, the Hi8 video records were first converted to MPEG file format and then encapsulated in AVI (Audio Video Interleave) format to allow for the extraction of individual frames and their storage as a collection of JPEG or TIFF images. Subsequently, a grid of known size (10 $\times 10 \mathrm{~cm}$ ) was computed and overlain on every image.

Nine 29-s video clips (each corresponding to 435 individual frames) were selected by image quality from the entire collection captured during the haul. Burrows were counted within a limited area of $0.5 \mathrm{~m}^{2}(1.0 \times 0.5 \mathrm{~m})$ in each frame image (Fig. 3), corresponding to a high confidence area (Correia 


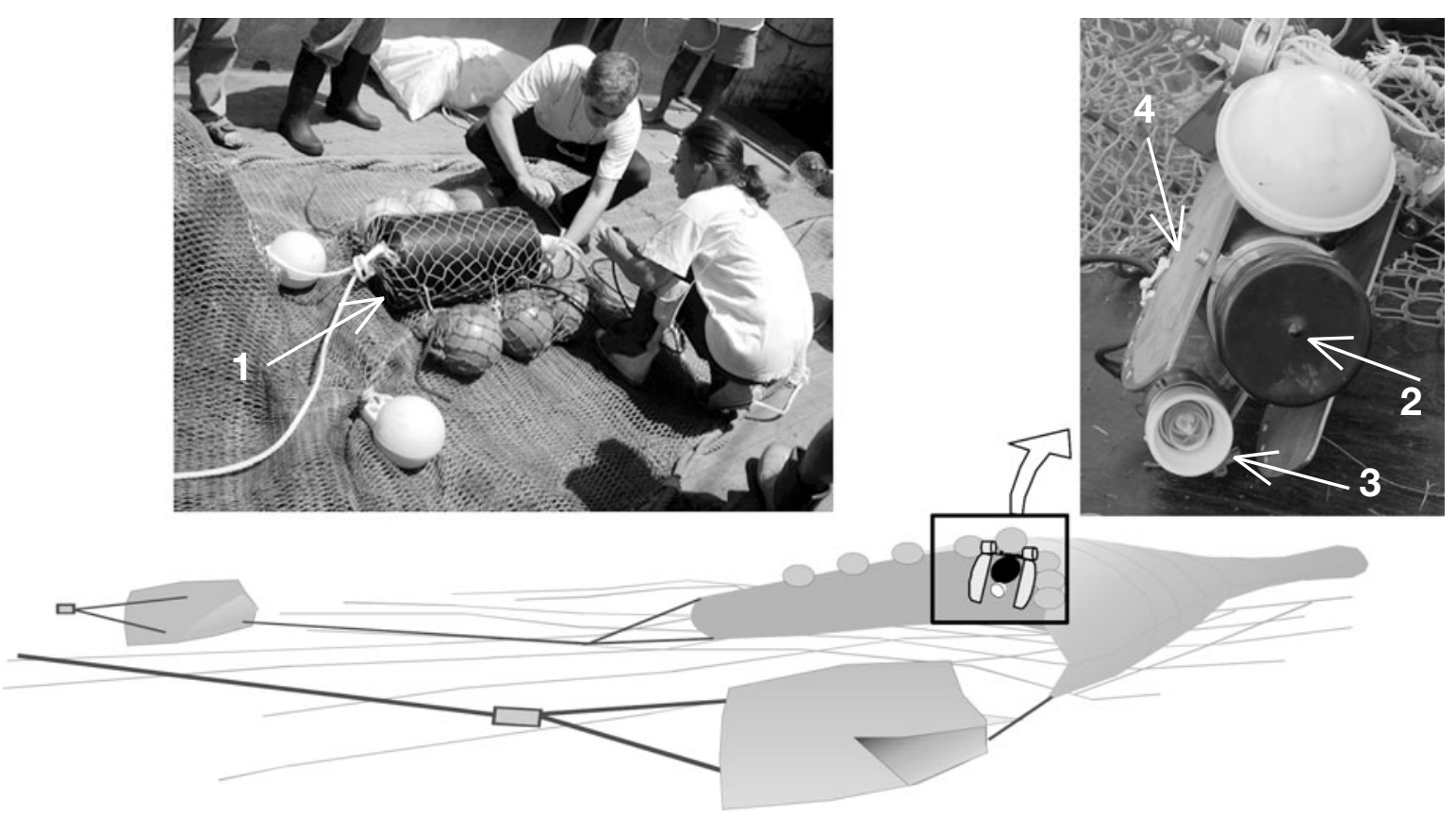

Fig. 2. Detail of the experimental set-up. The camera is hung in the centre of the trawl headline (trawl picture adapted from Valdemarsen \& Suuronen 2003, courtesy of Iconex 2001). 1: recorder and energy unit casing; 2: video camera with protecting cap; 3: $75 \mathrm{~W}$ lamp; 4: metal frame

et al. 2007) outside which there is image distortion due to wide-aperture camera lens characteristics and insufficient lighting. The overall area used for burrow density estimation was about $403 \mathrm{~m}^{2}$, representing $7.3 \%$ of the total confidence area covered by the tow.

Burrow identification as either 'entrance' or 'secondary opening' in each non-overlapping $0.5 \mathrm{~m}^{2}$ rectangle was based on analysis of all frames relative to the area delimited by that rectangle, rather than on a single frame as initially intended. Otherwise, the identification of those located at the upper limit of the rectangular area would produce ambiguous results. Following this procedure, burrow (entrance) densities were estimated for each video clip and finally averaged.

\section{RESULTS}

The images analysed display a dense network of burrows, indicating a mature population inhabiting complex burrow systems, each burrow of which is assumed to have a single entrance and several secondary openings (see Fig. 3). Both the entrances and the secondary openings had an approximately circular shape. Secondary openings had diameters of $\sim 10 \mathrm{~cm}$ while entrances measured $\sim 20 \mathrm{~cm}$ across their 'crater-shaped' outer margin.

An average burrow (entrance) density of $2.1 \mathrm{~m}^{-2}$ (SD: $0.98)$ was estimated. The estimate is preliminary since
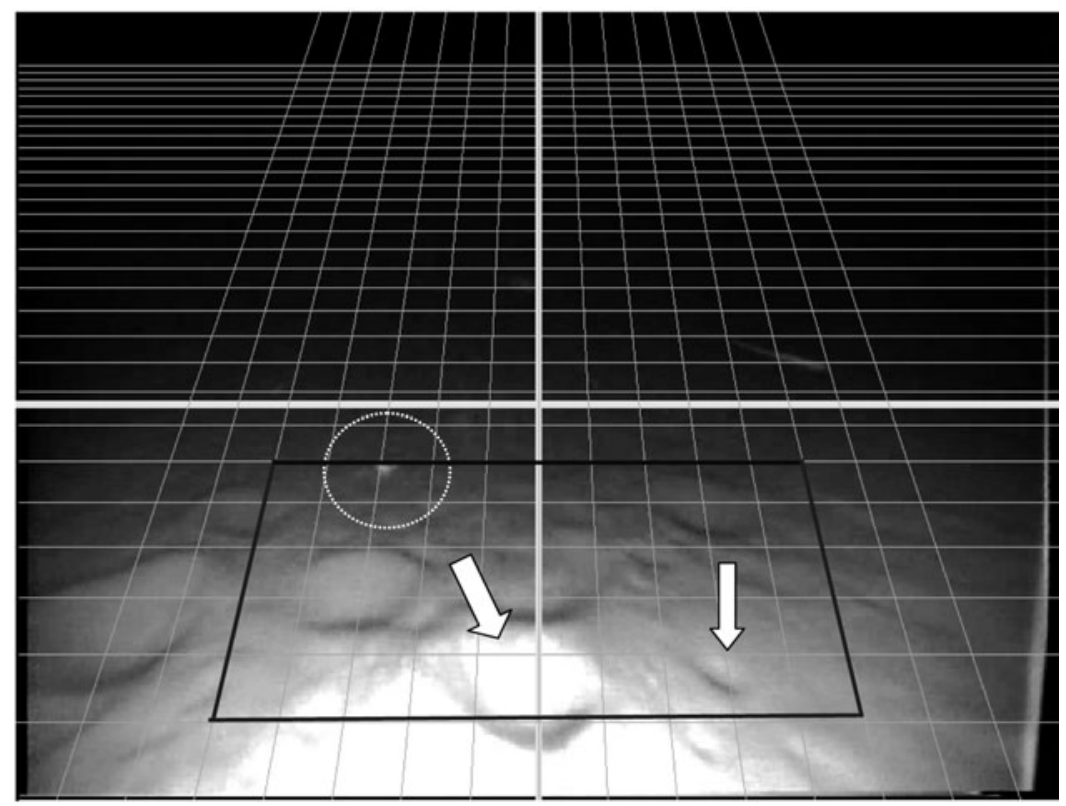

Fig. 3. Example of the 'Canadian grid' overlain on a single image. The black rectangle in the image encloses an area of $0.5 \mathrm{~m}^{2}$. The wider and thinner arrows indicate a primary burrow (entrance) and secondary opening, respectively. A lobster is enclosed by the dotted circle 
it was based on the analysis of a reduced area in a single tow. A total of 14 lobsters were detected (out of their burrows) along the track filmed, corresponding to a density of lobsters $84 \mathrm{ha}^{-1}$. The density estimated from the fishing catch over the entire tow was $39 \mathrm{ha}^{-1}$. Assuming that all the observed lobsters were caught (a reasonable assumption since they were in line with the centre of the gear) the overall gear efficiency (caught lobsters as a proportion of those available in the path of the gear) was about 0.46. In addition, assuming that each burrow system was occupied by a single adult lobster, an instantaneous rate of emergence (proportion of out-of-burrow lobsters in the total population) estimate of $2.3 \%$ was calculated.

\section{DISCUSSION}

The experimental set-up and image analysis methodology presented are potential alternatives to the use of video cameras installed on dedicated devices (e.g. sledges, ROVs [remotely operated vehicles]). We envisage our set-up being used for habitat identification and mapping, for the estimation of epibenthic species abundance and the impacts of human activities in marine ecosystems.

The advantages of our set-up may be manifested in a variety of circumstances. First, it allows optimal use of vessel time allocated to other primary objectives, or it can be adopted when simultaneous estimates of trawl catches (of the recorded species) are sought. Under these circumstances, a comparison of video counts and actual catch figures may allow estimation of trawl efficiency. Furthermore, the methodology can be adopted under operational conditions where the use of a sledge may not be recommended (e.g. on very deep or irregular fishing grounds where keeping a sledge stable would be difficult).

A number of technical issues require future analysis, namely video format conversion, camera stability and burrow counting procedures. Since completion of our field work, the somewhat lengthy procedure of analog video conversion has been made simpler and faster by upgrading to a digital recording unit, which also prevents image degradation in the analog to digital conversion. Because the trawl gear is a flexible system, the inclination and elevation of the camera may change in relation to the seafloor. Accordingly, acoustic sensors are essential for monitoring significant positional variations while towing. Likewise, trawl speed affects image sharpness. Depending on bottom compactness, mud clouds raised by the otterboards may further contribute to reduced image clarity. However, trawl speed cannot be altered without affecting gear (and thus catch) performance and mud clouds are unavoidable.
Under these conditions, manual analysis by counting burrows (or lobsters) on images is not only tedious work, but demands a high degree of mental concentration from the operator. A potential alternative whose viability has already been demonstrated is application of image analysis software to automatically identify benthic species (Correia et al. 2007). Using segments from the haul analysed herein, Correia et al. (2007) showed that the Norway lobsters visible on the video can be automatically detected and counted. Norway lobster abundance estimates rely on burrow counts (or, more precisely, individual 'systems' of burrows), not the individual lobsters, which adds further difficulties to adoption of an automatic procedure. These difficulties are 2-fold: (1) identifying the burrows, and (2) differentiating between primary (entrances) and secondary openings. The first is the object of work in progress (Lau et al. 2007), but developing an algorithm to reliably separate main entrances from ventilation openings may prove difficult to achieve.

Acknowledgements. The images were collected during a survey carried out within the scope of the project 'Fishing Technologies' (MARE-QCAIII, 22-05-01-FDR-00014), which is the responsibility of INRB/IPIMAR Fishing Technology Department. We are grateful to Vesa Tschernij (Iconex, Finland) for authorising the use of the trawl picture in Fig. 2. P.F. acknowledges the contribution of the $\mathrm{PhD}$ student $\mathrm{F}$. Leotte in designing the camera mounting system prototype.

\section{LITERATURE CITED}

Aguzzi J, Bozzano A, Sarda F (2004) First observations on the Nephrops norvegicus (L.) burrow densities on the continental shelf off the Catalan coast. Crustaceana 77:299-310

Bailey N, Chapman CJ, Kinnear JB, Weetman A (1993) Estimation of Nephrops stock biomass on the Fladen ground by TV survey. ICES Document CM 1993/K: 34, ICES, Copenhagen

Correia PL, Lau PY, Fonseca P, Campos A (2007) Underwater video analysis for Norway lobster stock quantification using multiple visual attention features. Proc 15th Eur Signal Processing Conference, EUSIPCO'2007, September 3-7, European Association for Signal Processing, Poznan, Poland, p 1764-1768

EC (European Commission) (2005) Council Regulation No. 2166/2005 of 20 December 2005, establishing measures for the recovery of the Southern hake and Norway lobster stocks in the Cantabrian Sea and Western Iberian peninsula and amending Regulation (EC) No 850/98 for the conservation of fishery resources through technical measures for the protection of juveniles of marine organisms. Commission of the European Communities, Brussels. Available at: http://eur-lex.europa.eu/LexUriServ/LexUri Serv.do?uri=OJ:L:2005:345:0005:0010:EN:PDF

Fonseca P, Campos A, Mendes B, Fonseca T (2006) Development of selective grids for the Portuguese crustacean fishery: a contribution for responsible fishing. In: Guedes Soares C, Gonçalves de Brito V (eds) Inovação e Desenvolvimento nas Actividades Marítimas, Edições Salamandra, Lisboa, 2006 (in Portuguese) 
Grassle JF, Sanders HL, Hessler RR, Rowe GT, McLellan T (1975) Pattern and zonation: a study of the bathyal megafauna using the research submersible ALVIN. Deep-Sea Res 22:457-481

Lau PY, Correia PL, Fonseca P, Campos A (2007) Underwater image analysis to classify benthic habitat characteristics. Proc 13th Portuguese Conference on Pattern Recognition, Associação Portuguesa de Reconhecimento de Padrões (APRP), Lisboa, 2007

Lauth RR, Ianelli J, Wakefield WW (2004a) Estimating the size selectivity and catching efficiency of a survey bottom trawl for thornyheads, Sebastolobus spp., using a towed video camera sledge. Fish Res 70:27-37

Lauth RR, Wakefield WW, Smith K (2004b) Estimating the density of thornyheads, Sebastolobus spp., using a towed video camera sled. Fish Res 70:39-48

Morello EB, Froglia C, Atkinson RJA (2007) Underwater television as a fishery-independent method for stock assess-

Editorial responsibility: Jana Davis,

Annapolis, Maryland, USA ment of Norway lobster (Nephrops norvegicus) in the central Adriatic Sea (Italy). ICES J Mar Sci 64:1116-1123

Smith CJ, Marrs SJ, Atkinson RJA, Papadopoulou KN, Hills JM (2003) Underwater television for fisheries-independent stock assessment of Nephrops norvegicus from the Aegean (eastern Mediterranean) Sea. Mar Ecol Prog Ser 256:161-170

Tuck ID, Chapman CJ, Atkinson RJA, Bailey N, Smith RSM (1997) A comparison of methods for stock assessment of the Norway lobster, Nephrops norvegicus, in the Firth of Clyde. Fish Res 32:89-100

Valdemarsen JW, Suuronen P (2003) Modifying fishing gear to achieve ecosystem objectives. In: Sinclair M, Valdimarsson $\mathrm{G}$ (eds) Responsible fisheries in the marine ecosystem. FAO, Rome, and CABI International Publishing, Cambridge, p 321-341

> Wakefield WW, Genin A (1987) The use of Canadian (perspective) grid in deep-sea photography. Deep-Sea Res 34: $469-478$

Submitted: November 11, 2007; Accepted: June 16, 2008 Proofs received from author(s): September 17, 2008 